\title{
An Analysis on Female Education Level, Income and Fertility Rate in China
}

\author{
Jinfang Song ${ }^{1, a^{*}}$, Yaoqiu Kuang ${ }^{2, b}$ \\ ${ }^{1}$ Department of Economics and Management, Shantou Polytechnic, Shantou 515000, Guangdong, China \\ ${ }^{2}$ Guangdong Key Laboratory of Environmental Pollution and Health, School of Environment, Jinan University, Guangzhou 511443, \\ Guangdong, China
}

\begin{abstract}
The present population economic theories are all established at a hypothesis: parents are fully rational in decisions at every birth. The hypothesis is actually contradicted with the reality. This paper attempts to explain the fertility behavior of persons with different cultural degrees and income levels without the fully rational hypothesis. The paper puts forward a hypothesis that fertility rate has negative correlation with cultural degree, and proves it through two routes. One is higher cultural degree means longer education duration, which must occupy female reproductive period. The other route is that persons who get higher cultural degree are generally more rational, therefore less accidental pregnancy and childbearing occur.
\end{abstract}

\section{Introduction}

Nowadays, population growth and its interactions with the surrounding economic environment attract much attention from governments, research institutes and scholars. Economists contributed much on population theories, because population plays important role in economic behaviors as producers as well as consumers. Since it is only through the combined effect of fertility, mortality and migration, that the size of population changes, any analysis of the links between the economy and population growth must identify the economic factors responsible for changes in the behavior of these three components, especially fertility behavior. The principal effort by economists has been to develop mainly micro-economic models of fertility based on the theory of consumer choice.

The microeconomic theory of fertility could be discerned as: the "Chicago School Model," "Leibenstein's Model" and "Easterlin's Theories." All the economists whose work draws on Becker's two seminal papers, "An Economic Analysis of Fertility" and "A Theory of the Allocation of Time," or whose work has been inspired by it as the "Chicago School." The "Chicago School" theories attempt to explain the fertility behavior of families with particular emphasis on the United States. The Chicago model assumes children to be consumer durable goods from which parents consume a flow of services. Parents are considered to be rational, calculating cost and benefits at every birth, and as a result the model has something to say about the spacing of children[1-3]. Leibenstein considers children to be "commitment goods." This means that expenditures on children reflect a commitment undertaken by parents and not the temporary feeling toward the child at any moment[4-7]. Easterlin has two different theories of fertility: the "relative income hypothesis" and the "threshold of fertility regulation" hypothesis. The relative income hypothesis is intended to explain the post World War II baby boom in the United States[8-10], while the latter is intended to explain the high fertility rates in the less developed countries.

The present population economics theories are established on a common hypothesis. That is, parents are thoroughly rational in making decision at every birth. However, people could not be fully rational in reality, especially in fertility behavior. Natural affection, impulsion and some other perceptual factors occupy a huge part in fertility behavior. This paper attempts to explain the fertility behavior of persons with different cultural degrees without the fully rational hypothesis.

\section{Longer Education Duration Occupying Reproductive Period}

China has been carrying out family planning policy since 1970s, to coordinate the development of population with the development of the economy, society, resources and environment. The main contents of the policy are: Advocating delayed marriage ( 25 years old for man and 23 years old for woman) and delayed child bearing, fewer and healthier births; and advocating one child for one couple. Some rural couples with actual difficulties are allowed to give birth to a second child a few years after the birth of their first child[11].

Cultural degree has an obvious positive correlation with the education duration. That means the persons who

\footnotetext{
${ }^{*}$ Corresponding author: ${ }^{a}$ jfsong@ $@$ stpt.edu.cn

${ }^{\mathrm{b}}$ kuangyaoqiu@jnu.edu.cn
} 
get higher cultural degree generally spend more time in accepting education. Women average education duration influences fertility rate by occupying the easiest reproductive period. The women aged in 18-45 years old are discerned as reproductive, and the pregnants who are over 30 years old as aged puerperas in China. Generally, the most suitable fertile period is during 19-29 years old for a woman physiologically. In China, a person would be 23 years old generally when he or she finishes college education, and 26 years old when he or she gets master degree. Longer education duration must occupy the fertile period.

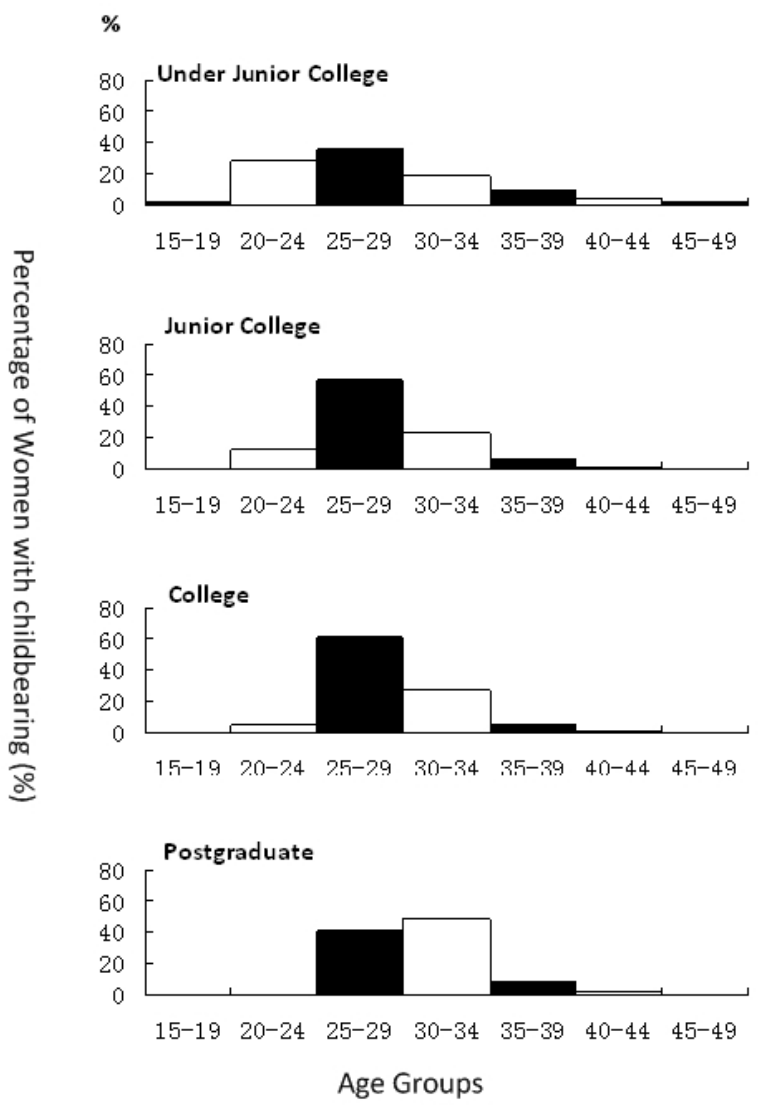

Chart 1 Age Group Proportion of women with childbearing at different cultural degree in Guangdong province

Delimited by college education, ages of the first childbearing for women with lower-than-college education are mainly controlled by family planning policy[12-13]. Women with above-college education generally married at ages older than 23 years old (They are 23 years old when they finish college education), beyond the limitation of family planning policy. Chart 1 is about childbearing age of women with different education degree in Guangdong province according to China's sixth national census. The chart indicates that women's childbearing age barycenter become elder with higher education degree. Among the women who has given birth for babies in 2010 in Guangdong, 29.8\% of those has lower that junior college education degree was younger than 25 , but only $12.6 \%$ of those has junior college education degree was younger than 25 . Just $5 \%$ of graduates that had gave birth to children in 2010 in Guangdong province was younger than 25 and none of graduates younger than 25, according to the chart. 25-29 is the childbearing emphasis for all women except female postgraduates. However, less than $36 \%$ of the women with lower than junior college education degree who gave birth to children were 25-29 years old, because of a big proportion were less than 25 years old. $56-60 \%$ of the women with junior or college education degree who gave birth to children were $25-29$ years old. About $50 \%$ of the women with postgraduate degree gave birth to children at 30-34 years old.

\section{Longer Education Duration Leading to Less Childbearing}

Shorter fertile period must lead to less child bearing with no consideration of policy limitation. Table 1 is about the average number of babies per woman with different cultural degree gave birth to and the average number of children per woman has in Guangdong province, according to the sixth census in 2010. The table indicates the negative correlation between women's education duration and their childbearing times. That means, the women with longer education duration gave birth to less babies and those with shorter education duration more.

Table 1 Women's Cultural Degree and Average Childbearing times in Guangdong

\begin{tabular}{|l|c|c|}
\hline & $\begin{array}{l}\text { Average Number } \\
\text { of Babies per } \\
\text { Woman Born }\end{array}$ & $\begin{array}{l}\text { Average Number } \\
\text { of Children per } \\
\text { Woman Has }\end{array}$ \\
\hline With no School Education & 2.86 & 2.82 \\
\hline Primary School Education & 2.39 & 2.37 \\
\hline $\begin{array}{l}\text { Junior Middle School } \\
\text { Education }\end{array}$ & 1.27 & 1.26 \\
\hline $\begin{array}{l}\text { Senior Middle School } \\
\text { Education }\end{array}$ & 0.66 & 0.65 \\
\hline Junior College & 0.53 & 0.53 \\
\hline Undergraduate & 0.42 & 0.41 \\
\hline Postgraduate & 0.44 & 0.44 \\
\hline
\end{tabular}

\section{Hypothesis}

Cultural degree is expected to impose huge influence on rationality therefore on fertility behavior. The parents who get higher cultural degree are expected to be more rational in fertility behavior, such as deciding whether they would procreate or how many babies they should procreate[14]. Moreover, the persons who get higher cultural degree have clearer plans for life development stages, and they know more on effective contraception[15]. Thus we conclude a hypothesis: fertility rate has a negative correlation with cultural degree. This paper attempts to prove the hypothesis with demographic data from China.

\section{Data sources, Method and Process}

\subsection{Data Sources}

Demographic data in the paper is all from China's six 
census and provincial Population and Family Planning Commission. China carried out six census so far, in 1953, 1964, 1982, 1990, 2000 and 2010. Other data is from China Statistical Yearbook and Guangdong Statistical Yearbook.

Besides demographic data from the whole China, the paper also takes data from Guangdong province and Shanghai municipality. Guangdong province locates in southern China. It is the biggest province with economy as well as population in China. However, there's severe unbalanced development within Guangdong province on economy, education and population, representative for China. Shanghai municipality is the biggest city and one of the most developed regions in China.

\subsection{Method and Process}

The paper attempts to prove the hypothesis through two routes. Firstly, the persons who get higher cultural degree are generally more rational, therefore less accidental pregnancy would occur on them. The paper makes a scatter diagram of cross-section data of women's average education duration and fertility rate in China's 31 provinces and municipalities.

For the other route, persons who get higher cultural degree must spend longer time in accepting education, which would occupy women's reproductive period. The paper makes a linear regression of education duration and women's ages of their first childbearing in Shanghai.

\section{Linear regression}

\subsection{Education Duration and Fertility Rate}

Chart 2 is a scatter diagram of cross-section data of average education duration of women over 6 years old and fertility rate in China's 31 provinces and municipalities, according to data from the sixth census. The scatter diagram indicates that fertility rate has obvious negative correlation with women's average education duration, with bad liner fit. The bad liner fit is estimated to be caused by China's family planning policy. The policy has been becoming the most important influencing factor for fertility behavior in China.

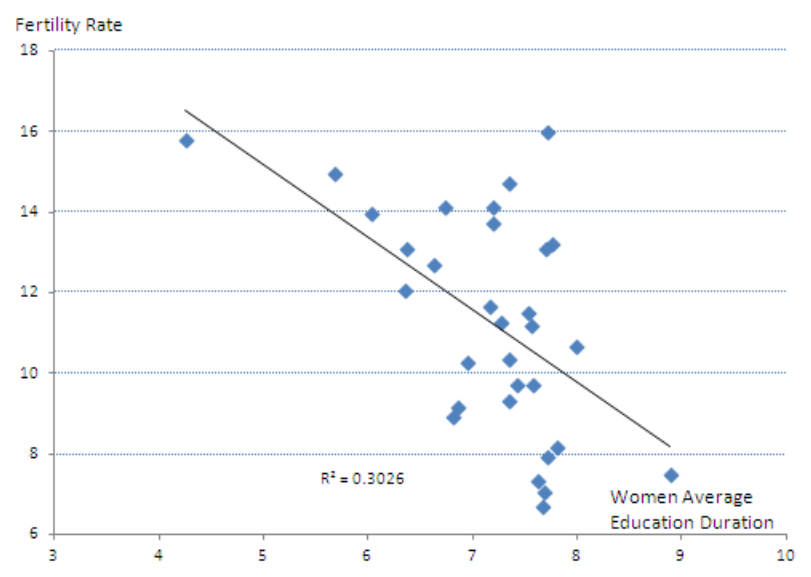

Chart 2 The Scatter Diagram of Fertility Rate and Women Average Education Duration in China

\subsection{Education Duration and Age of First Childbearing}

In order to exclude the interference from family planning policy, it's necessary to analyze the first childbearing age at different cultural degree. Education duration or cultural degree should be one of the major influence factors on their age of the first childbearing. It has important significance to study women's cultural degree and their age of the first childbearing.

To study the correlation of the age of the first childbearing and women's cultural degree, the paper makes a linear regression analysis with the average age of first childbearing and average education period of women in the 10 administrative districts in Shanghai municipality. The data is from Shanghai Population and Family Planning Commission.

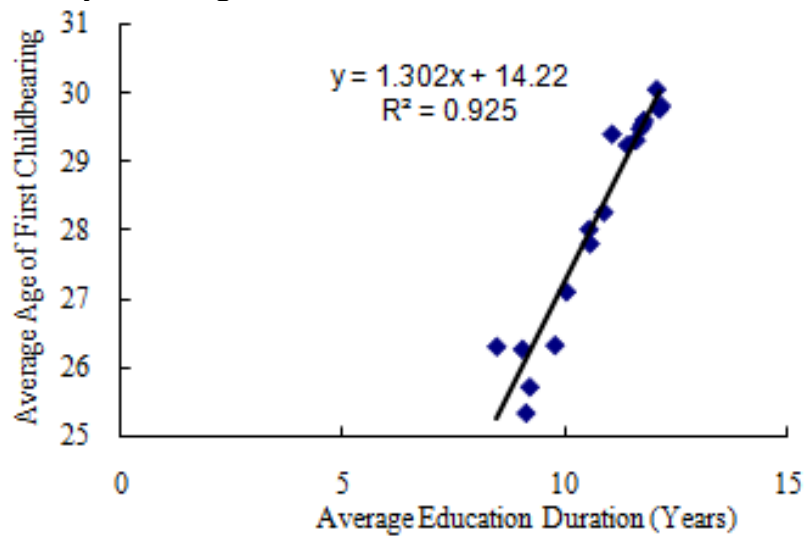

Chart 3 Linear Regression of Education Duration and Age of First Childbearing

Chart 3 shows that the average age of the first childbearing has obvious positive liner correlation with women average education duration. The average age of first childbearing is set as Y. the women average education period is set as $\mathrm{X}$. The regression equation as: $\mathrm{Y}=1.3028 \mathrm{X}+14.223$

The multiple correlation coefficient of $\mathrm{Y}$ and $\mathrm{X}$ is $\mathrm{R} 2=0.9258$. The check result compared with critical value, showed as Table 2, R2 is larger than the critical value 0.708 with a significance of 0.001 . There exists a remarkable liner correlation between $\mathrm{Y}$ and $\mathrm{X}$. That means, women who get longer education duration have elder age of the first childbearing. Extending the education duration is effective on postponing age of the first childbearing and therefore lowing fertility rate. The hypothesis that fertility rate has a negative correlation with cultural degree is proved true.

Table 2 check result of Linear Regression

\begin{tabular}{|c|c|c|c|}
\hline $\mathrm{R}^{2}$ & Sample Number & Freedom & Critical Value (0.001) \\
\hline 0.9258 & 18 & 16 & 0.708 \\
\hline
\end{tabular}

\section{Discussion and Conclusion}

Women's age of the first childbearing has positive correlation with women's education duration. Longer education duration can occupy the suitable reproductive 
period. Thus education duration has negative correlation with fertility rate generally. Longer education duration means lower fertility rate. Thus the authors view that it's better to popularize college education instead of the current family planning policy in China.

The present family planning policy in China could postpone women's age of the first childbearing to 24 . However, popularizing college education could postpone women's age of the first childbearing to at least 25 . Popularizing college education is more effective on lowering population fertility rate than family planning policy. The countries with higher people average cultural degree all record later first childbearing. The records are 28-30 years old in Japan, South Korea, Singapore and China's Taiwan, Hong Kong and Shanghai[16].

Beside control birth rate through postponing the age of first childbearing, popularizing college education could also benefit population quality sustainably. Mothers with higher cultural degree can provide healthy pregnancy and scientific nurture as well as better family education.

In addition, taking popularizing college education instead of family planning policy can improve China's human right record.

\section{Acknowledgments}

This work was supported by the Guangdong Provincial Science and Technology Innovation Strategy Special Fund Project No. 180916114960425.

\section{References}

1. Becker, G. S. (1960) An economic analysis of fertility, demographic and economic change in developed countries: a conference of the universities. National Bureau Commitee for Economic Research, 209.

2. Becker, G. S.(1965) A Theory of the Allocation of Time. Economic Journal, 75, 229, September: 493-517.

3. Becker, G. S. and Lewis, Gregg, H.(1973) On the Interaction between the Quantity and Quality of Children, Journal of Political Economy, 81, 2, Part II, March/April: 279-88.

4. Leibenstein, H(1957) Economic Backwardness and Economic Growth: Studies in the Theory of Economic Development. John Wiley, New York.

5. Leibenstein, H.(1975) The Economic Theory of Fertility Decline. Quarterly Journal of Economics, 84, 1: 1-31.

6. Leibenstein, H.(1974) An Interpretation of the Economic Theory of Fertility: Promising Path of Blind Alley?. Journal of Economic Literature, 12, 2: 457-479.

7. Leibenstein, H.(1975) On the Economic Theory of Fertility Behavior: A Reply to Keeley. Journal of Economic Literature, 13, 2: 469-472.
8. Easterlin, R. (1968) Population, Labor Force and Long Swing in Economic Growth: The American Experience. Princeton University Press, Princeton.

9. Easterlin, R.(1969) Toward a Socioeconomic Theory of Fertility: A Survey of Recent Research on Economic Factors in American Fertility. In: Behram J. E., Leslie Corsa and Ronald Freedman, Fertility and Family Planning: A World View. University of Michigan Press, Ann Arbor. pp. 127-156.

10. Easterlin, R(1973) The Economics and Sociology of Fertility: A Synthesis, revised version, University of Pennsylvania, Philadelphia.

11. Li TP, Guo XB.(2009) Effects of Birth Control Policy on China's Economic Growth in the Long Run: An Overview. Journal of China University of Geosciences (Social Sciences Edition), 9(06): 7-13.

12. The Research Team of "Childbearing Desire and Behavior in Jiangsu"(2008) A Study of the Child-Bearing Desire with a Low Fertility Rate. Jiangsu Social Sciences, 02:170-177.

13. Zheng ZZ.(2004) Fertility Desire of Married Women in China. Chinese Journal of Population Science, 5: 75-80+82.

14. Zhou X, Wang F.(2010) Women's Socio-economic Characteristic and Fertility Decision-making in China. Population Journal, 4:18-22.

15. Feng XT, Zhang QS.(2002) Study on the Transition of Fertility Desire among Rural and Urban Residents in the Past Twenty Years. Market \& Demographic Analysis, 8(5): 21-31.

16. Tu JC. (2006) Fertility Transition, Gender Equality and Policy Options in Hong Kong. Population Research, 30(3): 10-15.

17. Zhang KS \& Gu JS. (2020) The Effect of Fertility on Employment for Women in China. Population \& Economics, 242(5): 19-29. 